\title{
Armando Cotarelo Valledor, editor e estudioso do romanceiro tradicional galego
}

\author{
José Luís Forneiro \\ Universidade de Santiago de Compostela
}

\begin{abstract}
Resumo:
Armando Cotarelo Valledor tentou converter-se na maior figura intelectual do galeguismo da sua época, com este fim apropriou-se dalguns textos romancísticos recolhidos pelo advogado e folclorista Alfonso Hervella Courel. Na manipulação e nas glosas destes romances transparece a ideologia ultraconservadora deste filólogo de inícios do século XX.
\end{abstract}

\section{Palabras chave:}

Romanceiro. História da literatura galega. História do nacionalismo galego.

\begin{abstract}
:
Armando Cotarelo Valledor, a philologist of the beginning of XX c., tried to become the most important intellectual figure of the galeguismo of his time. With this intention he appropriated some of the ballads, which were collected by the lawyer and folklorist Alfonso Hervella Courel. The ultraconservative ideology of this philologist is evident in the manipulation and the notes of these ballads.
\end{abstract}

Key words:

Collection of ballads. History of the Galician literature. History of the Galician nationalism.

Armando Cotarelo Valledor (Veiga do Eu, 1879-Madrid, 1950) provavelmente seja, na actualidade, uma das figuras menos interessantes da cultura galega moderna. A sua erudição rancia, a artificiosidade da sua obra literária, o facto de ter sido redigida em língua castelhana a maior parte da sua produção intelectual, a sua adesão ao golpe militar de 1936 e, até, o seu físico pouco atraente, fazem com que este vulto do galeguismo das primeiras décadas do século XX mal interesse hoje ao mundo cultural galego. No entanto, desde a sua chegada a Santiago de Compostela em Outubro de 1904, foi uma das mais singulares figuras públicas na Galiza do seu tempo, pois actou como um decidido renovador da estagnada universidade compostelana de princípios do século passado (Barreiro 1984: 5-8), e este espírito modernizador não se limitou às aulas e à política universitária, uma vez que Cotarelo se destacou na vida social de Compostela pelo seu convívio com 
os estudantes (Filgueira 1984: 12) e até porque se deslocava pela cidade apostólica de bicicleta (Carvalho Calero 1984: 11). Mas Armando Cotarelo foi conhecido, principalmente, na Galiza das primeiras décadas do século XX, por ter participado nalgumas empresas políticas ${ }^{1}$ e, sobretudo, como animador da vida cultural, já que, entre outros cargos, foi secretário da Exposição Regional de 1909, presidente do Ateneu León XXIII e do Seminário de Estudos Galegos² e director das revistas El Centenario e Ultreya.

Cotarelo Valledor, na sua estada em terras galegas, que decorreria durante mais de três décadas (1904-1939), ocupou-se, nomeadamente, de contribuir para a produção teatral em língua galega e também de estudar diversos aspectos da história e da literatura da Galiza. A literatura popular não foi alheia aos seus interesses, destarte, não só editou ou dedicou páginas de estudo às composições literárias com que o povo galego acompanhava os seus momentos de labor e de lazer (o conto, a lírica e o romance tradicional), como também incorporou este tipo de literatura às suas obras de criação.

Em 1919, Cotarelo publica na Ultreya, "Revista Quincenal de Cultura Galaica", um artigo intitulado "Romancero popular gallego", onde pretendia

recoger en estas páginas cuantos romances de Galicia lleguen a nuestras manos, pues de este modo pensamos servir de alguna utilidad a quien haya de emprender el estudio y publicación del Romancero popular gallego que falta en nuestra región. [...]

Existe, sin embargo, caudal de este curioso género literario, viviente en boca del pueblo gallego, y de él poseemos algunas muestras que deseamos acrecer con las comunicaciones de amigos, discípulos y amantes de Galicia. Todas serán incluidas en la Revista, expresando la procedencia y nombre del colaborador (Cotarelo 1919: 33).

Uma vez manifestada a sua intenção de dar a lume quantos textos do acervo romancístico pudessem chegar às suas maos, Cotarelo julgava que

Aunque todavía consideramos prematuro, a lo menos para nosotros, el análisis de los romances galaicos, no debemos omitir ligeras consideraciones generales sobre ellos, para ilustración y recordanza de cuantos gusten favorecer esta empresa con sus aportamientos y sus luces (Cotarelo 1919: 33).

1 Foi eleito deputado pelo partido liberal em 1919 (Barreiro 1984: 8) e organizou uma frente eleitoral nos inícios da República de 1931 (Fernán Vello e Pillado Mayor, 1986: 46).

2 Membros do Seminário de Estudos Galegos como Ricardo Carvalho Calero, José Filgueira Valverde e Ramón Martínez López reconheceram o magistério intelectual de Cotarelo na instituição. 
Como vemos, o nosso autor pretendia aqui oferecer uma visão geral do romanceiro galego e ao tempo converter-se na máxima autoridade na matéria. Assim, Armando Cotarelo dava conta das colecções e das publicações realizadas até ao momento, e informava, de modo esquemático, sobre diversos aspectos do romance na Galiza como o nome, a classificação (pela linguagem, pela origem, pelo assunto), o mérito, o número, a datação, o assunto, os títulos, a tranmissão, o estado e a música. Nas duas páginas em que se ocupava de todas estas questões, Cotarelo só se mostrava em parte devedor das teses de Manuel Murguia, o maior estudioso deste género na Galiza do século XIX. Este afirmara inicialmente que o romanceiro era um género literário pouco conhecido na Galiza, para passar poucos anos depois a reconhecer a sua vitalidade e riqueza, chegando a afirmar que, para além dos romances de procedência castelhana, os de versos de oito sílabas, o saber folclórico galego atesourava canções narrativas mais antigas, baladas de origens celta e germânica, em versos hexassilábicos e heptassilábicos. Do marido de Rosalia de Castro, Cotarelo fez próprias ideias como a da pobreza numérica e poética do romanceiro face a outros géneros tradicionais e a da escassa presença na tradição da Galiza do verso romancístico por excelência, o verso octossilábico. No entanto, no que se refere ao aparecimento do romanceiro na Galiza, don Armando desentendia-se de improváveis origens pré-romanas ou suevas para assumir a sua importação do centro peninsular e assim, afirmava, baseando-se em Menéndez Pelayo, que os romances derivaram dos velhos cantares de gesta da Castela de fins do século XIV ou de princípios do século seguinte, e os mais antigos provavelmente chegaram à Galiza no século XV (Cotarelo 1919: 34).

Na realidade, esta como as outras informações e afirmações contidas neste trabalho (se exceptuarmos as já referidas de Murguia e as relativas à música dos romances) estavam tomadas da introdução que Alfonso Hervella Courel redigiu para o seu Romances populares gallegos recogidos de la tradición oral. Este advogado, nascido em Viana do Bolo em 188633, apresentara em 1909 a sua colecção de romances, obtida na sua terra natal, à Exposición Regional Gallega, de que Armando Cotarelo era secretário. Porém, este no seu artigo "Romancero popular gallego" não cita em nenhum momento o trabalho do estudioso ourensano como fonte informativa. De facto, na segunda nota de rodapé que aparecia em Romancero popular gallego, as palavras de Cotarelo pareciam indicar que já não estava em seu poder o romanceiro de Hervella:

3 Expresso aqui o meu agradecimento a Alfonso Mato, do Seminário de Estudos Galegos, e a Álvaro Armesto, juiz de paz de Viana do Bolo, as informações que tão atentamente me forneceram sobre este esquecido vianês. 
En la Exposición regional gallega celebrada en Santiago en 1909, tuvimos el gusto de examinar este conjunto de romances, todos recogidos de la tradición oral de la provincia de Orense. El autor residía entonces en Viana del Bollo a donde se le devolvió el manuscrito y es hoy dignísimo notario de Monforte (Cotarelo 1919: 33).

Resulta suspeitoso que Cotarelo indicasse neste artigo que todas as versões que lhe fossem enviadas "serán incluidas en la Revista, expresando la procedencia y nombre del colaborador", e que no caso de Hervella chegasse a proporcionar uma informação, em princípio desnecessária: que o manuscrito que ele conhecera como secretário da Exposição de 1909, lhe fora devolvido ao seu autor, todo "un dignísimo notario" da vila de Monforte de Lemos. Parece que Cotarelo, valendo-se do seu papel social e intelectual na Galiza do seu tempo, pretendia ser o "coordinador geral" na edição do romanceiro galego que Alfonso Hervella demandava no prefácio da sua colectânea:

Yo espero que algún literato pacienzudo y discreto recoja y seleccione aquellos de nuestros mejores romances que están esparcidos por las cuatro provincias gallegas y forme con ellos una más completa colección que esta que hoy ofrezco a mis paisanos. La labor es delicada y merece que anden en ella manos expertas y cuidadosas (Hervella 1909: II-III).

Daí que Don Armando expressasse claramente a sua vontade de proclamar-se como o maior especialista no romanceiro galego no final do seu artigo:

Sin duda que la presente colección debía de sujetarse a algún orden, adoptada una clasificación previa de los romances gallegos; mas para esto sería preciso conocerlos todos o por lo menos en su mayor parte, y aunque poseemos no despreciable caudal, fáltannos seguramente muchísimos, que iremos sumando con el favor de los entusiastas, peritos y amantes de Galicia a quienes, ahora y siempre, suplicamos ayuda y consejo. Los daremos, pues, a la publicidad conforme nos sea posible y lleguen a nuestro conocimiento, ya que aun desordenada, esta colección ofrecerá la ventaja de presentar reunido lo que anda disperso y de hacer asequible lo inédito o poco notorio. Más tarde vendrá el clasificarlos, estudiarlos y disponerlos para la edición crítica y científica de tan curiosas manifestaciones del arte popular. Entretanto acopiemos materiales para ello (Cotarelo 1919: 36).

São, portanto, suspeitas estas excusationes non petitae sobre as origens das suas fontes, que se contradizem com o ocultamento de que a maioria das informações de "Romancero popular gallego" estava contida na introdução do romanceiro inédito de Hervella, para além de nunca ter sido antes formulada por ninguém. Estas suposições tomam maior força se confrontarmos os textos publicados por Cotarelo com as versões da colecção de Hervella. 
Quando da altura da realização da nossa tese de doutoramento, El bilingüismo en el romancero tradicional gallego,${ }^{4}$ tivemos que analisar o romance de Tamar para ver qual a presença da língua galega neste tema, reparámos, após a leitura das duas versões recolhidas por Alfonso Hervella, que o texto deste romance publicado por Armando Cotarelo na revista Nós fora fabricado com as duas versões do primeiro devidamente retocadas. Tal descoberta levou-nos a comparar os romances publicados por Cotarelo, em que ele aparecia como colector, com as versões da colectânea de Hervella e, em praticamente todos os casos, verificámos que os textos dados a lume pelo erudito da Veiga do Eu também eram devedores dos romances obtidos por Hervella Courel.

Ignoramos se, realmente, lhe foi restituída a Alfonso Hervella a sua colecção de romances, mas muito provavelmente a cópia de que fala Armando Cotarelo é a que se conserva hoje no Museu de Ponte Vedra. Esta cópia é praticamente igual a que enviou a Ramón Menéndez Pidal, estando ambas datadas de 10/III/1909, ou seja, do ano em que se celebrou, em Santiago de Compostela, a Exposición Regional Gallega. ${ }^{5}$. Existe uma terceira cópia, um tanto diferente das anteriores, que foi a que Hervella Courel preparou como trabalho de ingresso no Seminário de Estudos Galegos, em 25 de Abril de 1927. Nesta terceira cópia, Hervella reduzia sensivelmente o estudo introdutório e o corpus textual por ele recolhido, bem como retocava os materiais romancísticos que obtivera da tradição oral (que nalguma ocasião atribuía a lugares donde não procediam os textos), não indicava o nome dos informantes e incorporava versões publicadas por outros autores, como António de la Iglesia. Por razões de acesso aos materiais podemos supor que Cotarelo conheceu as duas colecções depositadas nas instituições galegas, porém o facto de a maioria dos romances publicados por Cotarelo ver a luz antes do ingresso de Hervella no Seminário de Estudos Galegos, assim como as características dos textos publicados, é prova determinante de que Armando Cotarelo manuseou a cópia que se encontra hoje no Museu de Ponte Vedra, como veremos a seguir.

Para o confronto entre as versões obtidas por Hervella e as editadas por Cotarelo oferecemos como texto base os romances pertencentes à colecção do Museu de Ponte Vedra, indicando em notas de roda-pé as variantes que correspondem às cópias do Archivo Menéndez Pidal (AMP) e do Seminário de Estudos Galegos (SEG). Para mostrar com que versões da colecção de Hervella elaborou Cotarelo os seus textos, identificaremos cada uma delas com uma letra que antecederá o verso, hemistíquio ou partes do hemistíquio editados por Cotarelo. As variantes introduzidas por este são

4 Para tal fim, tivemos que estudar as mais de 6.000 versões dos mais de cento e sessenta temas que conformam o corpus, na sua maioria inédito, do romanceiro da Galiza.

5 As diferenças entre as duas colecções são mínimas e estão originadas pelo seu carácter manuscrito que inevitavelmente acarreta algumas divergências de cópia. A colectânea depositada na instituição pontevedresa faz parte do espólio de Casto Sampedro (IV Manuscritos: 5) (Filgueira 1988: 307). 
marcadas em itálico e respeitamos a ortografia e a pontuação originais de ambos os editores. Após evidenciar como o erudito da Veiga do Eu fabricou os seus romances, trataremos dos comentários que os acompanhavam, dado que são muito significativos de qual era a sua visão do romance tradicional e da cultura galega.

No artigo "Romancero popular gallego" Cotarelo completava o seu estudo com uma versão do tema intitulado pelo Seminario Menéndez Pidal no Indice General del Romancero (IGR) Una fatal ocasión, a que Hervella tinha dado o título de $A$ romeira, título conservado por Cotarelo.

\section{A romeira I (a)}

Rubiales (Viana del Bollo). Petra Fernández.

Por aqueles campos verdes linda romeira camiña.

2 Paseando s'iba, paseando ô estilo d'Andalucía; peinando s'iba, peinando c'un peine de prata fina.

4 Saya leva sobre saya; basquiña sobre basquiña; zapato leva picado que de lonxe relucía;

6 as medias leva de lana que parecen prata fina. Mirando s'iba, mirando mirando s'alguien la vîa,

8 vîra vîr un caballero que d'amor la pretendía. -Por Dios cho pido, caballero; por Dios y Santa María

10 que me deixes ir con honra á esta santa romería. -Non t'hei deixar ir con honra ou te hei de quital a vida.

12 Comienzan de vuelta en vuelta, puñal d'oro lle caía; la niña como descreita ${ }^{6}$ muy de presa lo erguía:

14 lo metió 'n-el lado esquierdo y el derecho le salía. -Por Dios cho pido, romeira; por Dios y Santa María,

16 que no digas en tu tierra ni tampoco en la mía que matach' un caballero con las armas qu' él traguía.

18 - Hache ser tan secreto com'a gaita en romería dind'a pirmeira ciudade hasta a última vila.

6 Mariño Ferro e L. Bernárdez (2002: 180) copiam mal discreita; igualmente não respeitam a contracção de $17 \mathrm{a}$ e transcrevem $q$. matache un $c$. Sobre a péssima qualidade e a falta total de critério científico do Romanceiro en lingua galega destes autores vid. a crítica de Forneiro (2002: 28) e a contrarréplica de Mariño e Bernárdez (2002 ${ }^{\text {b }}$ 28) onde amostram mais uma vez a sua incompetência no tema, além de evitar ou mascarar as críticas apontadas com um tom desrespeitoso. 


\section{Variantes AMP:}

14a: 1. m. n. 1. ezquierdo

\section{Variantes SEG:}

Quintela do Pando (Viana)

$\mathrm{O}$ verso 2 está elidido.

4b: ô uso de Andalucía

5b: q. p. seda f.

8: v. v. u. cabaleiro q. d. a. 1. requería

9: P. D. ch'o p. cabaleiro p. D. e S. M.

11b: que t. h. d . quitar a v.

12: Cabaleiro ô dar a volta p. d. ouro 1. c.

13: A nena c. d. m. d. p. o e.

14: meteull'o do lado esquerdo y o corazón lle partira 15b: p. D. e S. M.

16: q. non d. na tua terra nin tampouco na miña

17a: q. m. u. cabaleiro cu'as a. q. e. t.

19: dende a p. c. h. na u. v.

\section{A romeira II (b)}

Palleirós (Puebla de Trives). Josefa Hervella.

Por aqueles campos verdes linda romeira camina ${ }^{7}$.

2 Saya leva sobre saya basquiña sobre basquiña; zapato leva picado ô uso d'Andalucía;

4 peinando vai su cabello todo al doble le cubrira; media levaba encarnada que de lonxe relucía.

6 Mirando vai car' atrás, mirando s'alguen ${ }^{8}$ a vîa, la vîra un caballero de los que la pretendían.

\footnotetext{
7 camiña (Mariño \& Bernárdez 2002: 180).

8 alguien (Mariño \& Bernárdez 2002: 181).
} 
8 - Por Dios cho pido, cabaleiro; por Dios e Santa María que me deixes ir honrada a esa ${ }^{9}$ santa romería.

10 Anduveran volta á volta, puñal d'ouro lle caía. La niña como discreta lo levantó par' arriba,

12 lo metió tras de la espalda y el corazón le partira. -Por Dios cho pido, romeira; por Dios y Santa María

14 non-o digas 'n-a tua terra nin tampouco 'na miña que matach' un cabaleiro co' as armas qu' él traguía.

16 -Non cho direi, cabaleiro, hasta 'n-a pirmeira vila, qu' elí o hei de perdicar com'a gaita en romería.

18 En llegando á su casa ya su padre lo sabía que matara un cabaleiro co’ as armas qu' el traguía.

20 — ¡Oh, banhaya a romeira y a madre que la parira, que matóu un cabaleiro co'as armas qu' él traguía.

\section{Variantes AMP:}

Entre 9 e 10 figura o verso - Non t' hei deixar ir honrada, nin tampouco â romería.

\section{Variantes SEG:}

\section{San Esteban (Viana)}

1b: 1. r. camiña

4: p. v. s. cabeza c'un peine de prata fina

6: M. v. cara a. m. s’a. la vía

7b: d'aqueles qu'a p.

8a: P. D. ch'o p. c.

9b: a esta s. r.

Entre 9 e 10 figura o verso - Non t' hei deixar ir honrada, nin tampouco â romería.

11: A meniña qu'é d. ergueu'o logo pra riba

12: meteull'o por entr'as costas y o c. lle p.

13: p. D. ch'o p. r. p. D. e S. M.

9 esta (Mariño \& Bernárdez 2002: 181). 
14: que n. d. na t. t. n. t. na m.

15a: q. matache u. c.

16a: N. c. hei dicir, caballero

17a: que ch'a de ser tan secreto

18: Cando chegou â s. c. xa seu pai o sabía

19: q. m. u. caballero

20: O. banhayas tu, romeira, y a. m. q. te p.

21: q. matache u. c.

A romeira III (c)

San Mamed (Viana del Bollo). Vicenta Ramona Fernández.

Por aqueles campos verdes linda romeira camiña.

2 Saya leva sobre saya basquiña sobre basquiña;

zapato leva picado ô uso d'Andalucía;

4 peinando s'iba peinando con peines de prata fina.

Mirando se va, mirando, mirando s'alguién la vîa:

6 Vírala un caballero; d'amores la pretendía.

La niña como discreita, dejó d' andar y corría;

8 el caballero d'a caballo muy pronto l' alcanzaría ${ }^{10}$.

-Dame tu cuerpo, la blanca; dame tu cuerpo, la niña;

10 dame tu cuerpo, la blanca, sino te quito la vida.

-Por Dios cho pido, caballero; por Dios e Santa María,

12 que me deixes ir con honra á esta santa romería.

-Dame tu cuerpo, la blanca, dame tu cuerpo, la niña;

14 dame tu cuerpo, la blanca, sino te quito la vida.

La niña con el temblor dijo que se lo daría;

16 levanta saya de grana, baja su blanca camisa, se tiró 'n-un pozo hondo, donde la mar convertía

18 Todas las campanas tocan; todas tocan á alegría.

Unos dicen: ¿Qué será? y otros dicen: ¿qué sería?

20 Es la hija del caballero que para el cielo camina.

${ }^{10}$ la alcanzaría (Mariño \& Bernárdez 2002: 181). 


\section{A romeira $^{11}$}

aPor aqueles campos verdes linda romeira camiña,

2 bleva saya e sobresaya, basquiña sobre basquiña,

azapato leva picado $a$ estilo de Andalucía;

$4 \quad{ }^{\mathbf{b}}$ peiteando vai seus cabelos ${ }^{\mathrm{a}}$ con peine de prata fina, seus cabelos que de longos todo o alto lle cubrían.

6 bay mirando cara atráse mirando se alguén a vía; aben a viu un caballero que de amor $a$ prentendía.

$8 \quad{ }^{\mathrm{c}}$ A nena como discrenta en vez de andare corría; ${ }^{\mathbf{c}}$ cabaleiro de a cabalo axiña a alcanzaría.

10 De lonxe lle dice "agarda, agarda, agarda, la niña.

"Dame tu cuerpo, romera, sino te quito la vida"

12 a__Por Dios pido, caballero, por Dios e Santa María, "que me deixes ir con honra a esta santa romeiría."

14 a_"Ou te hey de quitar la honra ou te hey de quitar la vida" ${ }^{\mathrm{a}}$ Comenzou de volta en volta; $\quad{ }^{\mathrm{b}}$ puñal de ouro lle caía;

$16{ }^{\mathrm{ab}}$ a nena como discrenta desde o chan o recollía; 'bmeteullo pol' as espaldas y o corazón lle partía.

18 b__'Por Dios cho pido, romeira, por Dios e Santa María, ${ }^{a}$ que non digas en tu tierra $y^{\mathbf{b}}$ nin tampouco aen la mía,

20 aque matache un caballero con las armas que él traguía". b_."Non o direi, caballero, hasta na pirmeira vila,

22 "que che a de ser un secreto como gaita en romeiría." ${ }^{\mathbf{b}}$ En achegando a sua casa xa seu pai ben o sabía,

24 bque matara un caballero con as armas que el traguía. b_ ¡Oh, benhayas ti, romeira, benhayas ti, miña filla,

26 bque matache un caballero con as armas que él traguía.

Cotarelo acompanhava esta versão de Una fatal ocasión com a seguinte glosa:

Recogido de la tradición oral.

Poseemos cinco $^{12}$ versiones de este romance: las dos primeras se completan mutuamente; la tercera presenta bastantes castellanismos; la cuarta consigna

\footnotetext{
11 Os autores do Romanceiro en lingua galega não reparam em nenhum momento que a versão de Armando Cotarelo estava elaborada com os textos de Hervella (Mariño \& Bernárdez 2002: 176 e 180-182).

12 Indicar três em lugar de cinco, bem como o ambíguo recogido de la tradición oral anterior, são marcas para distanciar-se das suas fontes.
} 
algunos detalles obscenos innecesarios, y la quinta está contaminada por otro romance castellano moderno como se ve en el final: Dice hablando de la heroína:

Se tiró nun pozo hondo donde la mar convertía.

Todas las campanas tocan, todas tocan a alegría; unos dicen: “¿Qué será?” y otros dicen: “Qué sería?” - Es la hija del caballero que para el cielo camina ${ }^{13}$.

Con lo cual el argumento varía por completo.

Parece tratarse de un romance genuinamente gallego, parte de un ciclo que debió existir en torno a la romería de Santiago, y seguramente antiguo. Así lo indican toda su estructura, la repetición de ciertas frases y la acentuación paroxítona, para favorecer la cual acude a la adición de la e paragógica, sin necesidad, pues no afecta al asonante (verso 6$)^{14}$.

El verso 5 parece interpolado ${ }^{15}$. La primera mitad del 8 semeja sustitución de otro perdido; nótese su repitición(sic) en el ${ }^{16}$.

El 22 debe ser adición moderna. En los 12 y 18 contiene una frase imprecativa característica de los romances galaicos antiguos 16 y los 20, 24 y 26 el pensamiento fundamental de la composición. Véanse en los 7, 10, 11, 14, 19 y 20 muestras de lo advertido acerca del uso del castellano por los personajes exóticos o empingorotados que figuran en los romances ${ }^{17}$.

A nuestro juicio pueden suprimirse los versos $3,5^{18}, 8,9,14$ y 22 para la restauración del texto primitivo.

Em 1920, Armando Cotarelo inicia a série que prometera um ano antes e edita uma versão, publicada pela primeira vez em 1888 por António de la Iglesia, de La mala

13 Correspondem aos quatro versos finais da versão c de Hervella.

14 Ao nosso parecer, este $e$ paragógico foi incluído pelo próprio Cotarelo a fím de ligar este romance com a lírica medieval.

15 É criação total de Armando Cotarelo.

${ }^{16}$ Quais são esses romances galegos antigos? Cremos que aqui o nosso estudioso volta a tentar relacionar os romances com a lírica medieval, em concreto com as Cantigas de Santa Maria de Afonso X, obra a que já dedicara a sua atenção.

${ }^{17}$ Cotarelo castelhaniza os versos das versões de Hervella com o fim de que o texto reflicta de maneira simplista a identificação das classes altas com o castelhano e as classes baixas com o galego. Esta descrição da diglossia da sociedade galega, que Cotarelo retratou nas suas obras teatrais bilingues, não se produz necessariamente nos romances da Galiza.

18 Inventado por Cotarelo. No entanto, não lhe parece que o verso 10, também composto por ele, pudesse ser prescindível. 
suegra. Aqui, Cotarelo indica as referências bibliográficas do texto, uma versão que, como demonstrámos num trabalho anterior, não passava de ser um romance factício elaborado com materiais autênticos, que foram submetidos à manipulação (Forneiro 1999: 666).

Três anos depois, em 1923, Armando Cotarelo publica Sinxebra, peça teatral em língua galega, em que se incorporam versos de romances. Num dado momento, um grupo de rapazes canta o princípio do romance infantil Hilo de oro:

De Francia vengo, señora, de comprar hilo francés,

en el camino me han dicho que lindas hijas tenéis (Cotarelo 1923: 26)

Ambos os versos bem poderiam ser os da versão que Alfonso Hervella recolhera de Manuela Diéguez, em Santo Estevo (Viana do Bolo), com a correcção castelhanizadora de han dicho em lugar de dijeron do segundo verso, já que a única versão publicada deste tema, até esse momento, obtida por José Pérez Ballesteros, apresentava maiores diferenças ${ }^{19}$. Umas páginas depois aparece o verso -Me casó mi madre chiquita y bonita, do também romance infantil Me casó mi madre tema só recolhido na tradição oral da província de Lugo, portanto, talvez obtido pelo próprio Armando Cotarelo. Também na mesma página se encontram os seguintes versos, um arremedo do estilo do romanceiro tradicional, pois não correspondem a nenhum tema testemunhado na Galiza:

— ¿Por qué lloras, bella niña? —¿Por qué tengo de llorar?

Mi mamaíta se ha muerto, mi padre se va a casar

y a mí y a mis hermanitos madrastra nos quiere dar.

Por eso lloro, señora, ¡bien tengo por qué llorar! (Cotarelo 1923: 32)

Um ano depois, Cotarelo inclui noutra peça teatral, Lubicán, um romance, desta vez inteiro, onde nas páginas 11-13 imita o estilo do romanceiro tradicional. Antes da recitação deste romance a sua transmissora, a tia Miñota, menciona que conhece, entre outros, Delgadiña, San Xoán, A romeira, Frol da auga, Tres comadres $^{20}$, todos estes temas estavam presentes no trabalho de Alfonso Hervella.

19 De Francia vengo, señora, de un pulido portugués, en el camino me ha dicho que lindas hijas tenéis (Pérez Ballesteros 1884: 136)

${ }^{20}$ O título Tres comadres não aparece na lista de temas de "Romancero popular gallego". San Xoán e Frol da auga, são, provavelmente, o mesmo tema com títulos diferentes. 
Em 1925, Armando Cotarelo publica na revista Nós o artigo "Un romance galego", trabalho lido no Seminário de Estudos Galegos em 15/10/1924, nele, como já indicámos antes, editava uma versão do romance bíblico de Tamar $^{21}$, que não passava de ser um texto factício elaborado com duas versões recolhidas por Hervella. Eis os textos:

\section{El incestuoso I (a)}

Espino (La Vega). José Nieto Carracedo.

Tres hijos tenía el rey, todos tres com'una grana,

2 el más chiquitito d'elles se namoró d'una hermana.

Un día por la gozar s'hallaba malito en cama.

4 Bajara su padre á verlo d'altas torres dond' estaba.

— ¿Qué tienes tú, hijo mío? ¿qué es lo qu’ á ti te pasa?

6 -Calientura tengo, padre, calientura que no m'arranca.

— ¿Qué tomarás, hijo mío, qué tomarás que te 'o traiga?

8 -Un guisado, padre mío, que me lo hiciera mi hermana.

-Que lo haga, hijo mío; que te lo haga y que lo traiga.

10 —QQué tienes tú, hermanito, qu' estás tu malito en cama?

-Todo esto, mi hermana, tus amores me lo causan.

12 - Mis amores, hermanito, á ti no t'importan nada.

La cogió por la cintura y en la cama la echara;

14 voces daba la doncella á su padre que le valga.

-Cállate tu, hermanita, tod'esto no importa nada:

16 tenemos un tío en Roma que todo lo dispensaba.

\section{Variantes AMP:}

6b: c. q. n. m'arrama

\section{Variantes SEG:}

Palleirós (Puebla de Trives)

2a: e. m. pequeñito d'eles

${ }^{21}$ Esta versão sob o título de Torpinos (Versión recogida por Dn. Armando Cotarelo) foi incorporada à colecção (pp. 30-32) que o advogado salmantino Alejo Hernández obteve na cidade da Corunha e na sua periferia, e no norte de Lugo, durante os anos 1924-1925 e que hoje faz parte do Archivo Menéndez Pidal. 
6: Calentura t. p. calentura q. n. arrama

8a: U. g. mi padre

9b: q. t. 1. h. y 1. t.

15b: t. e. n. val n.

16b: q. t. esto d.

\section{El incestuoso II (b)}

Palleirós (Puebla de Trives). Josefa Hervella.

Tres hijos tenía el rey, todos tres como una grana;

2 el más chiquitito d'eles se namoró d'una hermana; para la vencer más presto s'hallara muy malo en cama.

4 Un domingo á la tarde vino por allí su madre. -¿Qué comerás, fillo meu? ¿qué comerás que ch’ eu traiga?

6 -La pechuga d'una pava si me la guisa mi hermana. -Eu lle direi que ch'a guise; eu lle direi que ch"a traiga.

8 -Si viene que venga sola, que no venga acompañada, que la bulla de la gente á los enfermos enfada.

10 Le cogiera la pechuga, la tirara por la sala; la cogió por los cabellos, por la sala l'arrastrara,

12 tanta burla fizo d'ela qu' hasta le cuspió en la cara. Se saíra car' afora la probe desconsolada.

14 -Justicia veña do Ceyo, qu'a da terra non val nada, pra matar o fillo do Rey que mi casa estropeara.

\section{Variantes AMP:}

1b: com'una grana

14a: Xusticia v. d. c.

\section{Variantes SEG:}

San Esteban (Viana del Bollo)

2a: e. m. pequeñito d. 
4b: su madre ond' el llegaba

6a: 1. p. de una p.

9a: porque el ruido d. $1 . \mathrm{g}$.

10: La cogió por la cintura y en la cama la echara

-¡Válgame pronto, mi padre, Válgame la Virgen Santa!

12: -t. b. hizo d'e.

13: Saliérase para fuera 1. pobre d.

15: p. matar o meu irmau q. mi honra me quitara

\section{Versão de Armando Cotarelo}

abTres hijos tiña este rey, todos tres com' una grana;

2 bel más chiquito de eles se namoró de una hirmana;

b para la vencer mas presto se hallara muy malo en cama.

4 aBajara su padre a verlo de altas torres onde estaba.

a__Qué tienes tú, hijo mío, qué es eso que a te ti pasa?

6 a_Calientura tengo, padre, calientura que no arranca.

b_ ¿Qué comerás, fillo meu? ¿qué comerás que eu che traia?

8 a_Un guisado, padre mío, ${ }^{\mathbf{b}}$ si me lo guisa mi hermana.

b_Eu llo direi que cho guise, eu llo direi que cho traia.

10 b_ Si viene que venga sola, que no venga acompañada, bque la bulla de la giente a los enfermos enfada.

12 a__Qué tienes tú, mi hermanito, qu' estás tan malito en cama?

a_Todo esto, hermana miña, tus amores me lo causan.

14 a_-Mis amores, hermanito, á ti no te importan nada.

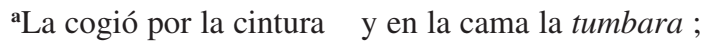

$16{ }^{\mathrm{a}}$ voces daba la doncella a su padre que la valga.

a_Cállate tu mi hermanita, todo esto no importa nada:

18 atenemos un tío en Roma que todo lo dispensaba.

bTanta burla fizo de ela que hasta le cuspió en la cara.

20 be saíra cara afora berrando desconsolada.

b_Xusticia veña do ceio, que a da terra non val nada,

22 bra matar fillo do Rei que a min me deixa bulrada. 
A 7 de Abril de 1928, Armando Cotarelo dá a lume O Pranto da Virxen numa página literária de El Compostelano, onde este romance tradicional estava acompanhado de poemas de Manuel de Sandoval, Teixeira de Pascoaes, Rafael Sanz de Diego, Luis Contreras e Guillermo F. Shaw ${ }^{22}$. O título com que Cotarelo identificava este tema era a tradução para galego de El llanto de la Virgen (Por las almenas del cielo no, $I G R$ ), como assim intitulara Alfonso Hervella as duas versões que obtivera na sua vila natal. Armando Cotarelo, aqui como nos dois casos anteriores, fabricou o seu texto misturando, ao mesmo tempo que alterando, as versões da colecção de Hervella.

\section{El llanto de la Virgen I (a)}

San Esteban (Viana del Bollo). Aquilina Carballo.

Por los caminos del Cielo s'apasea una doncella,

2 toda vestida de blanco, cubierta de gracia llena.

Preguntó San Juan a Cristo: “-¿Quién es aquella doncella?

4 Y Cristo le respondió:

-Aquella es Nuestra Madre, Nuestra Madre verdadera.

6 -Pues que es Nuestra Madre, adoremos todos 'n-ella;

Los angelitos del cielo y los hombres de la tierra

8 han visto llorar la Vírgen debajo d'una olivera.

— ¿Por qué llora usté, Señora? ¿por qué llora usté, doncella?

10 - Lloro por una noticia que me trougo Madalena:

que un hijo que yo tenía, que sin dolor lo pariera,

12 me lo están crucificando en una cruz de madera.

Un poquito más alante hay un sepulcro de piedra,

14 donde murió Jesucristo, Salvador de Cielo y tierra;

y un poquito más alante hay una cruz de madera,

16 donde murió Jesucristo, Salvador de Cielo y tierra;

no murió por sus pecados, que nunca los cometiera:

18 murió por los pecadores por nos dar la Gloria eterna.

22 A fotocópia desta página de El Compostelano (assim como outra da primeira página deste jornal de 31 de Março de 1927 em que Alfonso Hervella Courel publicava uma versão de La infantina,) foi-me oferecida por Armando Requeixo, a quem agradeço aqui a sua amabilidade. 


\section{Variantes SEG:}

1b: se apasea u. d.

4a: Elidido

5: P. qu'es N. M. todos adoremos 'n ella

\section{El llanto de la Virgen II (b)}

San Mamed (Viana del Bollo). José Casal.

Por los caminos del Cielo s'apasea una doncella,

2 toda vestida de sangre, cubierta de gracia llena.

Preguntó San Juan á Cristo: ¿Qué doncella es aquella?

4 -Pues aquella es Nuestra Madre, Nuestra Madre verdadera.

-Pues ya qu' es Nuestra Madre, todos adoremos 'n-ella.

6 Los angelitos del Cielo y los hombres de la tierra.

han visto llorar la Virgen por debajo d'una olivera.

8 - ¿Por qué llora usté, Señora? ¿Por qué llora usté, doncella?

Lloro por una noticia que me trajo Madalena;

10 por un hijo que 'o he tenido que sin dolor lo pariera, que está muerto 'n-una cruz, 'n una cruz de madera.

12 - Si me lo bajan devotos muy contenta m' estuviera; así con fuerzas me hallara que yo misma lo cogiera.

14 Allí 'n-el monte Calvario hay una cruz de madera, ond' está el Salvador, Salvador de Cielo y tierra;

16 no murió por sus pecados, que nunca ningun tuviera: murió por los pecadores por nos dar la Gloria eterna.

\section{O Pranto da Virxen}

"Recogido de la tradición oral, por Armando Cotarelo".

${ }^{\text {ab }}$ Polos camiños del Cielo se paseia una doncella,

2 atoda vestida de branco, coberta de gracia chea.

bPreguntó San Juan a Cristo: “- ¿Qué doncella será aquella?

4 b_Pos aquella es nuestra Madre, ${ }^{a}$ todos adoremos nella. 


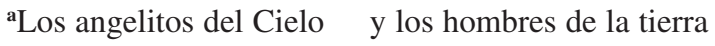

ahan visto chorar a Virxen debaixo de unha oliveira.

ab__Por qué chora usté, señora? ¿por qué chora, usté, doncella?

8 a_Choro por unha noticia que me trougo Madalena:

aque un hijo que yo tenía, que sin dolor lo pariera

${ }^{a}$ me lo están crucificando en una cruz de madera.

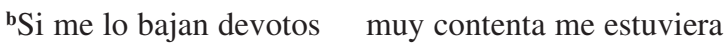

12 b y si con fuerzas me hallara yo mesmo lo recogiera

${ }^{a}$ que un poquito más alante hay un sepulcro de piedra.

14 bAllí en el monte Calvario está una cruz de madera

${ }^{a}$ donde murió Jesucristo Salvador de cielo y tierra.

16 aNo murió por sus pecados que nunca los cometiera,

${ }^{\mathbf{a b}}$ murió por los pecadores por nos dar la gloria eterna.

Ignoramos se Cotarelo publicou na imprensa mais textos procedentes do acervo coligido por Alfonso Hervella ${ }^{23}$, mas os três textos aqui analisados manifestam tanto a ultrapassada concepção do romanceiro tradicional de Armando Cotarelo, quanto a sua desonesta apropriação de materiais alheios. Os seus preconceitos classistas e letrados faziam com que considerasse que a tradição oral estropiava os textos que adoptava como próprios: “[...] los romances se hallan hoy atrozmente desfigurados, según ocurre con cuanto no se fija en la escritura” (Cotarelo, 1919: 35), "[...] este romance, como tantos otros, al transmitirse por tradición oral [...] ha sido notablemente desfigurado con repeticiones, interpolaciones, cambios de palabras y de tiempos de algunos verbos, supresiones, lagunas, etc. (Cotarelo 1920: 277), "[...] o romance amostra ser moi antigo, inda que a forma en que o puiden recoller háchase estragada de tanto peneirar de boca en boca" (Cotarelo, 1925: 2)

A consideração de a tradição oral corromper os romances que acolhia explica que a manipulação e o retoque dos textos por parte dos colectores e editores fosse prática comum na segunda década do século XIX e, nalguns casos, até nos primeiros anos do século XX. Todavia, o respeito pelos textos orais foi exigido pelos estudiosos positivistas das últimas décadas do século XIX. Assim, por exemplo, na Bretanha da década de 60 foi posta em causa a autenticidade do Barzaz Breizh (1839), colecção de baladas bretãs reunidas por Hersart de la Villemarqué (Postic 1997: 97-123). Por sua vez, o folclorista e dialectólogo sueco A. W. Munthe censurou, em 1888, que Juan Menéndez Pidal criasse versões factícias com os roman-

23 As bibliografias da sua obra não indicam de que Armando Cotarelo editasse mais romances (Barreiro 1984: 3-4 e Varela 1984: 135-148). 
ces tradicionais na sua Colección de los viejos romances asturianos (1885) (Cid, 1992: 45), a primeira colecção moderna importante em língua castelhana. O próprio Alfonso Hervella também foi um colector positivista da tradição oral galega como se pode comprovar no último parágrafo do prefácio dos seus Romances populares gallegos:

No terminaremos este ya enfadoso prólogo sin hacer constar que todas las versiones incluidas en esta colección son fidelísimas copias de las narraciones orales, que personalmente recogimos de labios de sus recitadores; con lo dicho queda asegurado que no hemos incurrido en el imperdonable vicio del amaño y el retoque. No hemos querido imitar a los románticos en lo de "dorar el oro y platear la plata de la poesia popular” (Hervella, 1909: XXIV).

Não deixa de resultar curioso que um advogado interessado pelo romanceiro da sua terra fosse um editor de romances mais científico ${ }^{24}$ que Armando Cotarelo Valledor, o principal filólogo galeguista das décadas de 20 e 30 do século passado. Se Cotarelo recorreu ao "vicio del amaño y del retoque" sobre os textos de Hervella, não só foi por julgar a literatura tradicional como um saber inferior à literatura considerada culta, pois também pretendia apropriar-se de materiais que lhe permitissem ser considerado o maior especialista nos romances galegos. Uma vez que Manuel Murguia se ocupara e sublinhara a importância deste género da literatura tradicional na cultura do país, e que Víctor Said Armesto (o homem de letras mais prestigioso na Galiza de inícios do século XX) recolhera entre 1900 e 1910 um excelente e riquíssimo romanceiro nas quatro províncias galegas ${ }^{25}$, Armando Cotarelo sentiu-se obrigado a tratar do romance de tradição oral no seu afã por ser o patriarca da cultura na Galiza daquela época.

No entanto, para além desta razão, cremos que o interesse de Cotarelo pela literatura popular também respondia à sua visão política, social e cultural da Galiza e da Espanha. Se repararmos nos assuntos dos três romances aqui analisados, podemos ver que todos têm uma relação mais ou menos directa com a religião católica. Deixando de lado o tema de $O$ Pranto da Virxen, pelo óbvio do seu assunto e porque Cotarelo não o acompanhou duma glosa, os romances de A romeira e de Tamar fornecem-nos reveladoras informações sobre a ideologia do nosso autor.

\footnotetext{
24 De qualquer modo, Alfonso Hervella nem sempre respondeu à manifestação positivista do seu prefácio; os seus preconceitos morais, devidos ao seu conservadorismo católico, explicam que nalguma ocasião suprimisse versos ou vocábulos dos romances pudoris causa, segundo as suas palavras.

${ }^{25}$ Cotarelo Valledor manifestou sobre a colecção de Said: "Hace años que vimos en Madrid esta colección en manos de su autor y nos pareció muy notable. Ignoramos su paradero. Algunos de los romances que contenía han sido publicados en diferentes ocasiones [...]” (Cotarelo, 1919: 33).
} 
No caso de A romeira Armando Cotarelo relacionava este romance, como já vimos, com o caminho de Santiago, baseando-se no facto de a protagonista ser uma romeira; porém, o tema carece duma qualidade especificamente galega, dado que é uma balada difundida em toda a Europa. A ligação deste romance com a matéria jacobeia, unia a reivindicação do seu carácter galego ao mesmo tempo que o seu valor religioso. Se o galeguismo progressista opôs desde a Geração Nós até aos nossos dias um Apóstolo Santiago europeísta e universalista ao tradicional Santiago matamouros do espanholismo mais castiço e integrista (Barros 1994, 253), isto não deve levar a pensar que Cotarelo, pelas suas actividades galeguistas nas primeiras décadas do século XX, não participasse da concepção do mito jacobeu própria do tradicionalismo espanhol.

Em nossa opinião, o abuso da identificação na historiografia galeguista da pósguerra do nacionalismo com a história da Galiza (Ventura 2000: 95 e Villares 1984: 164) e do uso da língua galega com valores progressistas e com atitudes "arredistas" ou anti-espanholas têm impedido a correcta compreensão de certas tendências no galeguismo ao longo da história, bem como dos percursos políticos e intelectuais dalguns vultos galeguistas. Hoje o nacionalismo galego costuma apagar no relato historiográfico tudo aquilo que não coincide com os seus actuais valores e, destarte, esquece ou minimiza a existência dum galeguismo conservador $^{26}$, surpreende-se perante a afervorada adesão dos regionalistas à causa espanhola durante a crise de 1898 (Casares 1998: 5-23), ou deixa de lado factos importantes numa biografia humana e intelectual como o uso exclusivo do castelhano por parte de Manuel Murguia e Rosalia de Castro no seu quotidiano (Durán 1977: 290-291).

O estudioso catalão Joaquim Ventura contestou recentemente no seu $O$ nacionalismo kármico de Vicente Risco (2000) a visão canónica do nacionalismo galego actual sobre a evolução ideológica deste vulto da cultura galega: de principal teorizador do galeguismo antes de 1936 a fascista converso a partir dessa data. No entanto, tal percurso ideológico, como muito bem demonstra Ventura, nunca teve lugar. Vicente Risco foi sempre o mesmo antes, durante e depois da sua experiência galeguista: um teósofo reaccionário temeroso das inovações materiais e intelectuais da sociedade contemporânea ocidental (Ventura 2000: 93-94; 118122). Nem foi progressista por aderir ao nacionalismo galego da pré-guerra, nem se tornou fascista a partir do golpe de estado do General Franco (Ventura 2000: 131-141). Neste sentido, o caso de Vicente Risco bem poderia ser o de Cotarelo Valledor.

${ }^{26}$ Se bem que seja indubitável que a tradição predominante no galeguismo contemporâneo tem sido a progressista, graças ao liberalismo de Murguia, Vilar Ponte e Castelao e ao desinteresse da Igreja galega pela língua e a cultura autóctones. 
O facto de Armando Cotarelo ter dinamizado a vida universitária, cultural e social na conservadora Compostela de princípios do século XX, ou de se comprometer com o galeguismo (presidindo o Seminário de Estudos Galegos e empregando a língua galega nos usos coloquiais (Filgueira 1984: 15 e Carvalho Calero 1981: 111) e literários), não devem levar a engano: a militância galeguista de Armando Cotarelo durante a sua estada na Galiza não era qualquer amostra de um progressismo que trairia apartir de Julho de 1936. Formado intelectualmente dentro das coordenadas ideológicas do integrismo hispânico (lembremos que era filho de Emilio Cotarelo Mori, um dos seus representantes mais notáveis junto a Marcelino Menéndez y Pelayo), Cotarelo foi sempre coerente com o seu conservadorismo inicial, fosse duma perspectiva espanhola ou galega. Daí que a sua "aventura" galeguista nunca contradissesse o seu espanholismo prévio e posterior, uma vez que o seu galeguismo nunca fora anti-espanhol nem o seu uso da língua galega acarretara grandes mudanças na sua praxe intelectual ${ }^{27}$. No editorial do primeiro número da revista Ultreya (1919) que ele dirigia (portanto, poucos anos antes de empregar o galego como língua literária), podiam ler-se estas significativas palavras sobre a relação entre a Galiza e a Espanha e sobre a língua galega:

Somos españolistas porque somos españoles y porque sabemos que cuanto se haga por España tanto se hará por Galicia, y somos regionalistas porque somos gallegos y por la convicción en que estamos a laborar por la gran patria española.

Por eso nosotros, aunque sentimos hondamente el habla gallega y anhelamos fomentar su empleo en determinados géneros de la literatura regional, no somos partidarios de su cooficialidad con el castellano, pues todo gran pueblo necesita de una gran lengua común para desarrollarse y consolidar su personalidad, y sería injusto negar tal prerrogativa a la lengua de Castilla, que tiene tan gloriosa historia y se habla por cien millones de habitantes en veinte florecientes estados (Cotarelo 1919: 2).

O uso coloquial da língua galega por Armando Cotarelo, de acordo com as novas práticas linguísticas dos galeguistas do século $\mathrm{XX}^{28}$ e a sua produção literária bilin-

${ }^{27}$ De facto, parece que a sua figura não suscitou adesões unânimes dentro do movimento galeguista: "Queda tamén sen aclarar cal é a súa verdadeira posición política na paisaxe política da época. A súa figura provoca nos galeguistas posicións encontradas, desde a gabanza ó ataque, que ben pagaría a pena pescudar. Sirva como mostra disto un significativo artigo de Villar Ponte no que afirma que "Nuestro ilustre amigo Don Armando Cotarelo no ha sido nunca capaz de entender a Risco ni entendernos a nosotros cuando hablamos de nacionalismo" (Boullón-Tato 1991: 40-41).

${ }^{28}$ Ao que parece, os escritores oitocentistas em língua galega nunca ou raramente empregavam a fala autóctone nos usos orais, segundo os testemunhos de Emilia Pardo Bazán (1984: 296) e de José de la Hermida, primo de Rosalia de Castro (Durán 1977: 290-291). 
gue ou em língua galega (peças teatrais de assunto histórico e sobretudo rural ${ }^{29}$ ), bem como alguns trabalhos científicos na língua do país (Cancioneiro da agulla, Un arcebispo de Santiago descoñecido, Etimoloxías populares, etc.), conviveram com o uso do castelhano nos seus romances e na maior parte da sua obra científica. Inclusive, como já vimos anteriormente, Cotarelo também praticou o bilinguismo quando manipulou o romanceiro tradicional ${ }^{30}$, à diferença de editores de romances do século XIX, como Murguia e Antonio de La Iglesia, que traduziam para galego tudo o que aparecesse em castelhano nos romances recolhidos do acervo popular.

Os galeguistas conservadores das primeiras décadas do século XX, Cotarelo, Vicente Risco, Filgueira Valverde ou Noriega Varela, não traíram a sua Galiza ideal por aderir ao General Franco a partir de 1936. Todos eles foram, de maneira quase inevitável, franquistas, porque perante tudo eram católicos integristas e daí que o seu galeguismo não passasse de ser a forma que numa dada altura certo integrismo espanhol adoptara para, desde la región, resistir às "devastações" da modernidade: o desenvolvimento tecnológico, a urbanização, o laicismo e as ideologias de esquerda.

Por outro lado, o galeguismo de Cotarelo era uma continuação do nacionalismo endocêntrico que caracterizou as aristocracias do Antigo Regime, que reivindicavam para as suas respectivas comunidades ser o berço das Espanhas. Uma vez que os bascos foram durante esse período histórico os depositários do essencialismo espanhol por sua limpeza de sangue semita ${ }^{31}$, para Cotarelo era inaceitável que na Espanha Contemporânea um povo do norte perdesse semelhante privilégio em favor dos andaluzes ${ }^{32}$, “os semitas espanhóis" por excelência. Em nossa opinião,

${ }^{29}$ São de interesse as seguintes palavras de Ramom Reimunde sobre Trebón, que bem se poderiam aplicar ao resto da produção literária de Armando Cotarelo: "Mais nom hai na sua obra Trebón nengum elemento de propaganda galeguista nem de sátira contra a desgaleguizaçom como outras do seu tempo (Mal de moitos, 1915), nem dado algum para conhecer a situaçom sócio-económica e cultural do campo em Galiza a começos do século XX" (Cotarelo, T: 37).

30 Também os dois grandes colectores de romances de princípios do século XX, Alfonso Hervella e Víctor Said, retocaram os romances que obtiveram da tradição oral empregando o galego e o castelhano.

31 Conforme a antropóloga flamenga Christiane Stallaert "el nacionalismo vasco, nacido por la competición por la limpieza de sangre, es el fruto más puro que ha producido el etnicismo español" (Álvarez Chillida 2002: 233).

${ }^{32}$ A identificação da Andaluzia com a Espanha foi criada polo Romantismo francês e inglês, após a derrota do exército de Napoleão na Península Ibérica. Sirva, de exemplo, o seguinte trecho de Félix de Azúa ao respeito: "Aquel viajero que a principios de siglo podía escribir impunemente: "Al fin me encuentro en Irún, es como Constantinopla', haría el ridículo si en el período post-napoleónico no fuera más al sur en busca de novedades. Así, poco a poco, por acumulación informativa y a medida que Vasconia, Cataluña o Valencia van viéndose como tierras enteramente normales, como cosa común y europea, aunque más pobre y aburrida; a medida que van dejándose de ver espectaculares primitivos en 
depois de o recém nascido nacionalismo basco rejeitar a espanholidade do seu país quando o liberalismo afundou a identidade castiça em Espanha (Álvarez 2002: 235), e dado que os andaluzes pelo seu passado muçulmano não eram, em termos rácicos, "de confiança", Cotarelo propunha que a Galiza preservasse na Espanha do século XX, as essências que caracterizaram a identidade espanhola durante a Idade Moderna: a limpeza de sangue e a religião católica.

Segundo Hannah Arendt, não existe uma relação filial entre o sentimento antijudeu próprio dos confrontamentos entre diferentes credos religiosos antes da Idade Contemporânea e o anti-semitismo, uma ideologia secular oitocentista que considerava os judeus na altura da crise do Estado-Nação europeu como um grupo antinacional pelo seu carácter internacional (Arendt 1968: 25). Porém, para outros estudiosos, o anti-semitismo moderno bebe do velho anti-judaísmo (Karady 2000: 210 e Álvarez Chillida 2002: 215). Seja como for, de acordo com Jon Juaristi, naqueles estados nacionais europeus que careciam duma minoria judia, como era o caso espanhol, procurou-se um grupo que ocupasse "o gueto vazio". Assim, para o tradicionalismo hispânico os liberais espanhóis substituíram os judeus, uma vez quebrado, com a Constituição de Cádis (1812), o pacto nacional da Época Moderna, baseado na unidade católica do povo espanhol e no seu correlato negativo, o anti-judaísmo (Juaristi 1994: 121-122) ${ }^{33}$. Conforme com isto tudo, parece claro que a assunção por Armando Cotarelo do anti-judaísmo do Antigo Regime tinha como objectivo neutralizar os liberais, a nova anti-Espanha que substituía a velha anti-Espanha árabe e judia. Isto explica o interesse pessoal e "regional" de Cotarelo quando reivindicava para a Galiza um papel de relevo na Espanha do século XX, pois o território galaico, livre de influências semíticas e caracterizado pelo seu secular isolamento, podia ser um firme baluarte na defesa dos "antergos" valores hispânicos face às dissolventes inovações intelectuais que acarretava a modernidade liberal.

Esta defesa do essencialismo rácico e religioso espanhol por Cotarelo patenteia-se em obras como Fray Diego de Deza (1902) e Límite septentrional de la conquista sarracena en España (1921). No primeiro destes livros, Armando Cotarelo ocupa-

Barcelona o en Alicante, Andalucía se dibuja como la última esperanza del romanticismo, como la verdadera patria. Y así, poco a poco, Andalucía se convierte en la super-España y los andaluces en superespañoles: hombres arcaicos de vida sexual libre (especialmente las mujeres por chocante que parezca), de extraordinarias aptitudes artísticas, ignorantes de su propia valía y viviendo en un paisaje salvaje de magníficos contrastes" (Azúa 1996: 165).

33 Os nacionalismos periféricos também julgaram que o semita, ou o considerado como tal, era um perigo para a coesão nacional. No nacionalismo galego já foi repetidamente assinalado o caso de Vicente Risco e há pouco foi apontado o anti-semitismo dalguns vultos do nacionalismo catalão (Marfany 1995: 197-201; Álvarez 2002: 240-249) e do nacionalismo basco (Juaristi (1994: 115-136; Karady 2000: 226; Álvarez 2002: 229-240). 
va-se de retratar a figura deste samorano, nascido em 1422 e de apelido galego (Cotarelo 1902: 18), que, além de mestre do príncipe Don Juan (filho dos Reis Católicos), foi catedrático em Salamanca, Bispo de Samora, Jaém e Palência, arcebispo de Sevilha e inquisidor geral. Segundo Cotarelo, não foi tão duro como o famoso Torquemada e

mostró siempre particular enemiga a los moriscos y cristianos nuevos procedentes de judíos; contra estos especialmente excitó a los Reyes Católicos, con motivo de haber venido a España varios distintos de los expulsados en 1492, y obtuvo Real Cédula despachada en 5 de Octubre de 1499, para que se extendiesen a ellos las providencias acordadas contra los otros.

Quiso también persuadir a los monarcas de que convenía poner Inquisición en Granada, pues los moriscos recién conversos abusaban de su falta y tornaban al mahometismo (Cotarelo 1902: 145) ${ }^{34}$.

Em Límite septentrional de la conquista sarracena en España, Armando Cotarelo seguia o modelo do seu admirado Francisco Codera (de quem publicou uma biografia em 1898) que em 1879 tracejara o limite da invasão sarracena na Catalunha, Aragão e Navarra. Cotarelo concluía na sua obra:

De manera que tratando de señalar el límite superior de la Conquista sarracena en España sin vacilar nos inclinamos a establecerla en la línea formada por la gran cordillera Cantábrica hasta la frontera gallega y en esta comarca por el río Miño hasta su desembocadura en el Océano Atlántico (Cotarelo 1921: 42).

A intenção anti-semita de ambos os trabalhos é inequívoca, e no segundo caso podemos supor que Cotarelo Valledor estava interessado em sublinhar que a sua terra natal nunca fora invadida por povos africanos. Este anti-semitismo também se pode encontrar no artigo "Un romance galego", concretamente na glosa em que Cotarelo comenta a versão do tema bíblico deTamar, onde manifesta, de maneira muito explícita, a sua aversão por judeus e mussulmanos, bem como a sua vontade por vincular a Galiza com Castela, o eixo de Espanha:

A importanza diste eixemplar rube de súpeto ô considerar que Menéndez Pelaio esquirbiu referíndose a certa mostra romancesca andaluza do mesmo asunto hachada en Osuna por Rodríguez Marín [...] "es el único romance popular que conozco sobre asuntos del Testamento Viejo" [...]. Agora ben. Si

\footnotetext{
34 “[...] Deza (a pesar de ser él mismo un marrano, de linaje converso por vía de hembra) aspiraba a una limpieza étnica de España mediante la desaparición (vía inquisitorial) de todos los cristianos nuevos procedentes de judíos o moriscos" (Catalán 1998: 100).
} 
comparamos o romance de Osuna co noso, temos que lle dare a iste grande superioridade. É mais longo, mais compreto, mais movido, mais dramático e segurísimamentes moi anterior. $\mathrm{O}$ andalus parez obra de algún xudeu ou mourisco, según acrara a anteposizón do artello al ô nome de Tamar. A sustitución de Amnón por Tarquino, o forzador de Lucrecia é un caso ben craro de iso que se chama contaminación entre dous temas, un de Ourente e outro de Oucidente ${ }^{35}$.

O noso poeta non fixo nada d'esto. Con soilo o recordo de aquela bárbara páxina do Libro de Reises, teceu unha refenda ${ }^{36}$ bárbara tamén culpa do asunto, pro mais xêral, mais humán e millor condida e desempenada. Eiquí non se ve rastro algún de arabismo ou xudaísmo; por isto quero creer que o romance non nasceu en chola semítica, senón que de Castela veu a Galiza onde os nosos paisans o aniparon garimosos e de Castela baixou a Andalucía onde ise mouro ou xudeu estragou nél de moi mal xorne (Cotarelo 1925: 3)

Em definitivo, no labor de Armando Cotarelo como editor e investigador da tradição romancística da Galiza, encontramos diversas chaves para melhor compreendermos a sua personalidade e a sua obra, apesar de o estudo do romanceiro ter ocupado um lugar secundário dentro da sua produção intelectual. A atenção do erudito da Veiga do Eu pelo romanceiro, obedecia, por um lado, à sua ânsia de protagonismo no mundo cultural galego de inícios do século XX, uma vez que o romance foi um tema a que Manuel Murguia dedicara grande atenção, e porque na primeira década do século XX se reuniram na Galiza duas excelentes colectâneas romancísticas: as organizadas por Said Armesto e por Hervella Courel. Portanto, Cotarelo não podia pôr de parte um tema tão vivo na sua época e daí que chegasse, desonestamente, a tirar partido dos materiais coligidos por Hervella a fim de tornar-se num dos maiores especialistas galegos na matéria. Além disto, Armando

35 Cotarelo copia aqui palavras de Menéndez Pelayo: "Puede ser obra de algún judío o morisco, como parece indicarlo la anteposición del artículo Al al nombre de Tamar. La sustitución de Amón por Taquino o Tarquino (¿el forzador de la romana Lucrecia?) es un caso de contaminación muy singular entre dos temas poéticos: uno de Oriente y otro de Occidente” (Menéndez Pelayo 1900: 197).

36 Esta "refenda" é uma má leitura. Na página VII do prefácio de Alfonso Hervella na cópia do seu romanceiro que enviou a Ramón Menéndez Pidal expõe: “[...] los romances genuinamente castellanos al ser interpretados por el pueblo gallego se hagan en cierto modo regionales e indígenas. Este carácter es más marcado, más propio y más exclusivo en aquellas cantigas ${ }^{(1)}$ que se han inspirado en la historia local [...] (1) Así se llaman en la región los romances y también historias, cantares, referidas”. Este referidas na cópia do romanceiro de Hervella depositada no Museu de Ponte Vedra (p. VIII) lê-se como refendas, e Cotarelo na sua peça teatral Lubicán, também usa esta palavra: Mozas: ¡A refenda, a refenda! T. Miñota: Pois a tergo ${ }^{\text {(sic) }}$ escollede: Delgadiña, San Xoán, A romeira, Frol d'auga, Tres comadres..." (Cotarelo 1924: 11). Esta estranha palavra foi incorporada por Eladio Rodríguez no seu dicionário e na antologia desta obra lexicográfica editada por La Voz de Galicia no Dia das Letras Galegas de 2001 é uma das palavras seleccionadas: "Refendas: Historias, contos, xeralmente de meigas e pantasmas" (Rodríguez 2001: 29). 
Cotarelo serviu-se do romanceiro para reivindicar o papel da Galiza na Espanha do seu tempo. Deste jeito, Cotarelo assumia o castelhanismo originário e lingüístico do romanceiro tradicional porque (à diferença da maioria dos galeguistas desde o século XIX) pretendia colocar a Galiza dentro do concerto das Espanhas como o lugar que, para além de ter preservado o melhor de Castela, como o romanceiro, era um repositório do mundo castiço espanhol, limpo das influências semitas de que tanto acusavam os andaluzes, "os mais espanhóis dos espanhóis" na Idade Contemporânea.

\section{Referências bibliográficas}

Alvarez Chillida, G. (2002): El antisemitismo en España. La imagen del judío (18122002) (Madrid: Marcial Pons).

Armando Cotarelo, $T=$ Reimunde R. (ed.) (1984): Armando Cotarelo, Trebón (s. 1.: AGAL).

Azúa, F. de (1996) = González Sáinz, J. A. (ed.): Azúa, F., "El mito de la Andalucía romántica" (1981), El aprendizaje de la decepción, (Barcelona: Anagrama).

Barreiro Fernández, X. R. (1984): "Cotarelo e a Universidade de Santiago", Revista Monográfica de Cultura, 1: 5-10 (A Coruña: A. C. "O Facho").

Barros, C. (1994): "Mitos de la historiografía galleguista”, Manuscrits, 12: 245-266.

Boullón Agrelo, A. I. e Tato Plaza, F. R. (1991): “A cátedra de Lingua e Literatura Galega da Universidade de Santiago: datos para a historia dunha reivindicación" em Brea, M. / Fernández Rei, F., Homenaxe ó profesor Constantino García, t. II: 33-53 (Santiago de Compostela: Universidade de Santiago de Compostela).

Carvalho Calero, R. (1984): "Homenage a Cotarelo", Revista Monográfica de Cultura, 1: 11-12 (A Coruña: A. C. "O Facho").

Carballo Calero, R. (1981) "O idioma no Seminário de Estudos Galegos", Problemas da Língua Galega (Lisboa: Sá da Costa).

Casares C. (1998): “O desastre de 1898 e os escritores galegos”, Grial, 137: 5-23.

Catalán D. (1998): "Permanencia de motivos y apertura de significados: Muerte del príncipe don Juan", Arte poética del romancero oral. Parte $2^{a}$.Memoria, invención, artificio (Madrid: Siglo XXI).

Cid J. A. (1992): "La Colección de los viejos romances asturianos (1885) de Juan Menéndez Pidal y su formación”, Asociación Brasileña de Estudios Hispánicos (Abeh), 2, 43-73. 
Cotarelo Valledor, A. (1902): Fray Diego de Deza (Madrid: Imprenta de José Perales y Martínez).

[Cotarelo Valledor, A.] (1919): "Peregrinos de un ideal", Ultreya, 1: 2.

Cotarelo Valledor, A. (1919): "Romancero popular gallego", Ultreya, 3: 33-37.

Cotarelo Valledor, A. (1920): "Romance popular gallego. Albuela", Ultreya, 18: $277-$ 279.

Cotarelo Valledor, A. (1921): Límite septentrional de la conquista sarracena en España (Santiago de Compostela: El Eco Franciscano).

Cotarelo Valledor, A. (1923): Sinxebra (Santiago: El Eco de Santiago).

Cotarelo Valledor, A. (1924): Lubicán. Conto dramático de lobos e de amores, en tres cadros en verso (Santiago: El Eco de Santiago).

Cotarelo Valledor, A. (1925): “Un romance galego”, Nós, 21: 2-3.

Cotarelo Valledor, A. (1928): “O pranto da Virxen”, El Compostelano.

Durán, J. A. (1977): Crónicas, 2. Entre el anarquismo y el librepensamiento (Madrid: Akal).

Fernán Vello, M. A./Pillado Mayor, F. (1986): Conversas en Compostela con Carvalho Calero, (Santiago de Compostela: Sotelo Blanco).

Filgueira Valverde, X. (1988): O arquivo do Museu de Pontevedra (Pontevedra: Museo de Pontevedra).

Forneiro Pérez, J. L. (1999): “José Pérez Ballesteros e o romanceiro tradicional galego", em Álvarez, R./ Vilavedra, D., Cinguidos por unha arela común. Homenaxe a Xesús Alonso Montero, t. II: 629-642 (Santiago de Compostela: Dpto. de Filoloxía Galega da Universidade de Santiago).

Forneiro, J. L. (2002): "Fora as vossas torpes maos do romanceiro galego", A Nosa Terra (5-9-02), 1.046: 28.

Hervella Courel, A. (1909): Romances populares gallegos recogidos de la tradición oral (inédito).

Juaristi, J. (1994): "El guetto vacío", em VV. AA., Auto de Terminación: 115-136 (Madrid: El País/Aguilar).

Karady, V. (2000): Los judíos en la modernidad europea. Experiencia de la violencia y utopía (Madrid: Siglo XXI).

Marfany, J.L. (1995): La cultura del catalanisme (Barcelona: Empúries). 
Mariño Ferro, X. R. / Bernárdez, C. L. (2002ª): Romanceiro en lingua galega (Vigo: Xerais).

Mariño Ferro, X. R. / Bernárdez, C. L. (2002 )): "Resposta a unha refutación", A Nosa Terra (26-9-02), 1.049: 28.

Menéndez Pelayo, M. (1900): Antología de poetas líricos castellanos, romances populares recogidos de la tradición oral, t. X (Madrid: Librería Hernando).

Pardo Bazán, E. (1984) [reimp. da ed. de 1888]: "Idioma o dialecto", De mi tierra (Vigo: Xerais).

Pérez Ballesteros, J. (1884): em VV. AA., Folklore Gallego. Miscelánea. Biblioteca de las Tradiciones Populares, vol. IV: 136-137 (Madrid: Fernando Fe).

Postic, F. (1997): "Le beau ou le vrai ou la difficile naissance en Bretagne et en France d'une science nouvelle: la littérature orale (1866-1868)", Estudos de Literatura Oral, 3, 97-123.

Rodríguez González, E. (2001): Fernández Valdehorras, C., Breviario Enciclopédico “don Eladio”. Lendas, historias e tradicións populares de Galicia (s. 1.: La Voz de Galicia).

Varela Orol C. (1984): “Aproximación á bibliografia de Armando Cotarelo Valledor”, em VV. AA.: A presencia de Armando Cotarelo en Galicia: 133-148 (Santiago de Compostela: Dirección Xeral de Cultura da Xunta de Galicia).

Ventura, J. (2000): O nacionalismo kármico de Vicente Risco (Santiago de Compostela: Laiovento).

Villares, R. (1984): Historia de Galicia (Vigo: Galaxia). 